\title{
A Utilização de Retalho Composto de Pele e Tecido Mamário na Reparação de Área Cruenta Resultante da Deiscência de Esternotomia em Cirurgia Cardíaca
}

\author{
Jaime Anger, Pedro Silvio Farsky, Vivian Lerner Amato, Cely Saad Abboud, Antonio Flávio \\ Sanches de Almeida, Renato T. Arnoni, Jarbas Jackson Dinkhuysen, Paulo P. Paulista
}

São Paulo, SP

\section{Objetivo}

Descrever nova técnica para a reparação de áreas cruentas resultantes de infecção e deiscência de esternotomia na cirurgia cardíaca em seis mulheres que, além de área cruenta extensa na região esternal, haviam sido submetidas a uma primeira reintervenção com recidiva.

\section{Métodos}

É descrita a técnica cirúrgica utilizada baseada em retalho triangular composto de pele e tecido mamário com base no sulco inframamário inferior, transposto para a área cruenta a fim fornecer uma cobertura de tecido bem vascularizado.

\section{Resultados}

São discutidos os diversos tratamentos da fase aguda e também de reconstrução nas deiscências de região esternal.

\section{Conclusão}

Este retalho preenche as necessidades em relação às dimensões da perda de tecido da área cruenta além de fornecer uma maior proteção contra infecção a uma área que, pela deiscência ocorrida, permaneceu por certo tempo exposta.

\section{Palavras-Chave}

esternotomia, cirurgia cardíaca, complicações, retalho, mama

Instituto Dante Pazzanese de Cardiologia de São Paulo

Endereço para Correspondência: Jaime Anger - Av. Brigadeiro Luiz

Antonio, 3889 - Cep 01401-001 - São Paulo - SP

E-mail: anger@uol.com.br

Recebido para Publicação em 28/11/2003

Aceito em 05/05/2004
A esternotomia mediana foi descrita, pela primeira vez, em 1957, como via de acesso na cirurgia cardíaca sendo desde então largamente utilizada. A deiscência desta incisão está associada a altos índices de morbi-mortalidade.

Em 1976, Lee e cols. ${ }^{1}$ descreveram o uso do grande omento para a cobertura desta falha mediastinal e, pouco depois, J urkiewicz e cols. ${ }^{2}$ descreveram a utilização de retalhos musculares. 0 uso destes tipos de retalhos favoreceu a reparação mais precoce das áreas cruentas e uma significativa redução dos índices de infecção crônica por acrescentar tecido vascularizado.

A conduta de desbridamento associado à utilização precoce e agressiva de antibióticos e, quando necessário, o uso de retalhos tem sido a base da terapêutica nos casos de deiscência de esternotomia nestes últimos 20 anos, reduzindo drasticamente os índices de morbi-mortalidade ${ }^{3-6}$.

A maioria das deiscências pode ser corrigida apenas com a ressutura das bordas após a melhora das condições dos tecidos envolvidos. Entretanto existem situações em que isto não é possível devido a perda de tecidos ou quando existe grande tensão exercida sobre a sutura final.

A indicação do tipo de retalho está relacionada à alteração presente. A discussão sobre a preferência entre um retalho muscular ou músculo-cutâneo e um retalho cutâneo está baseada na vascularização de cada um. Um tecido bastante irrigado poderia favorecer a erradicação da infecção e aumentar a vitalidade dos tecidos envolvidos, favorecendo uma estabilização mais rápida do processo infecioso e cicatricial.

Entretanto, como observamos em $1981^{7,8}$, ao estudar o resultado dos diferentes tipos de retalhos para o tratamento de úlceras por pressão, os retalhos cutâneos ou ainda compostos com outros tecidos podem ter a mesma eficácia dos retalhos musculares e, eventualmente, proporcionar um resultado estético melhor e mais efetivo. Os retalhos musculares seriam então uma opção no caso de recidivas.

Neste artigo apresentamos uma nova técnica na reconstrução de região esternal com retalhos compostos de tecido mamário em mulheres que obtiveram um resultado efetivo com menor morbidade e melhor qualidade que os retalhos musculares.

\section{Métodos}

Em 2001 foram realizadas 1445 cirurgias cardíacas por via esternal, sendo que 66 apresentaram infecção na região esternal 
e 15 acometimento de mediastino. Apresentaram deiscência parcial ou total da esternotomia 24 pacientes, que tiveram de ser ressuturados. Oito apresentaram recidiva da deiscência, sendo que em 6 foi utilizada a técnica de retalho composto de tecido mamário e nos dois restantes, utilizado o retalho de avanço músculo-cutâneo de músculo peitoral maior.

Um retalho triangular de base proximal é demarcado na base da mama no sulco inframamário em contigüidade com a área cruenta. A base do retalho deve ter as mesmas dimensões da base da falha esternal e a altura igual ou maior que a área cruenta (fig. 1). 0 retalho é liberado e dissecado até a fáscia do músculo peitoral maior. Após a mobilização do retalho é feita uma incisão no sulco mamário, em sentido lateral, de dimensões que variam conforme a quantidade de tecido mamário existente e a elasticidade da pele, incisão esta que se estende até a fáscia e a mama é dissecada lateralmente no seu plano profundo. 0 tecido mamário deverá ser liberado e rodado em direção medial, preenchendo a falha doadora criada (fig. 2). Os planos são aproximados.

0 procedimento pode ser bilateral de acordo com as dimensões da área cruenta.

\section{Resultados}

Dos 6 casos operados, dois foram submetidos a procedimento bilateral. Dois pacientes apresentaram áreas de necrose superficial na extremidade distal do retalho de no máximo $1 \mathrm{~cm}$, com cicatrização espontânea e sem alteração do resultado final. Não ocorreram deiscências (fig. 3,4 e 5).

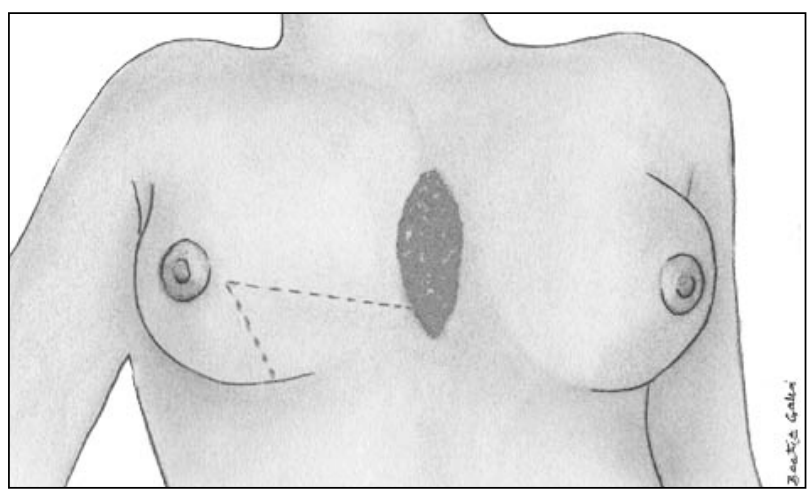

Fig. 1 - Esquema de marcação do retalho composto

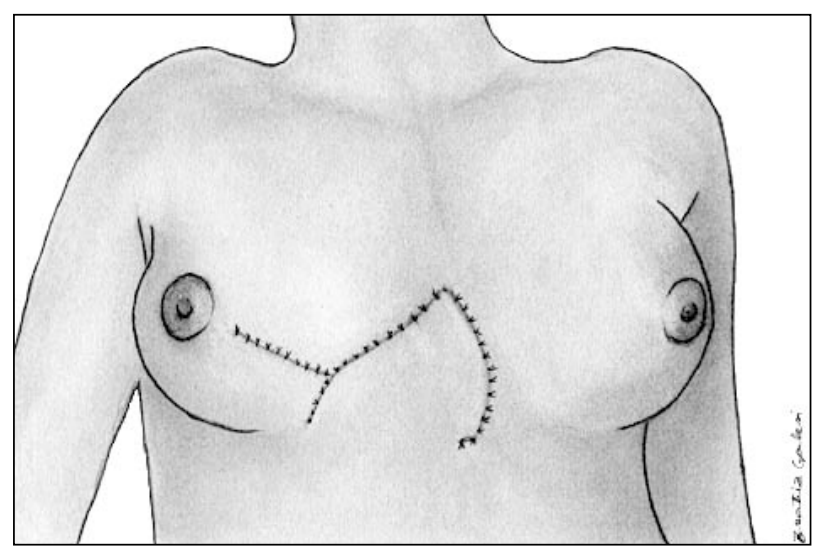

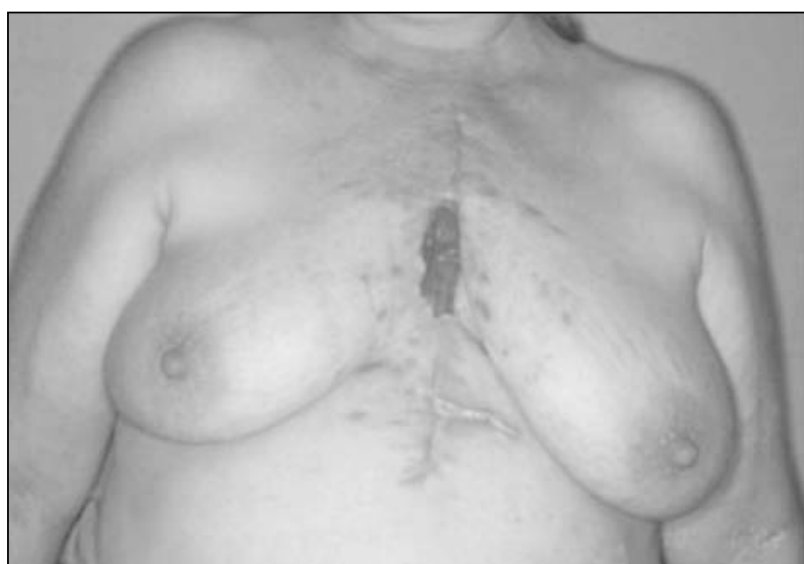

Fig. 3 - Paciente com deiscência secundária de esternotomia após ser ressuturada. Paciente em posição ortostática.

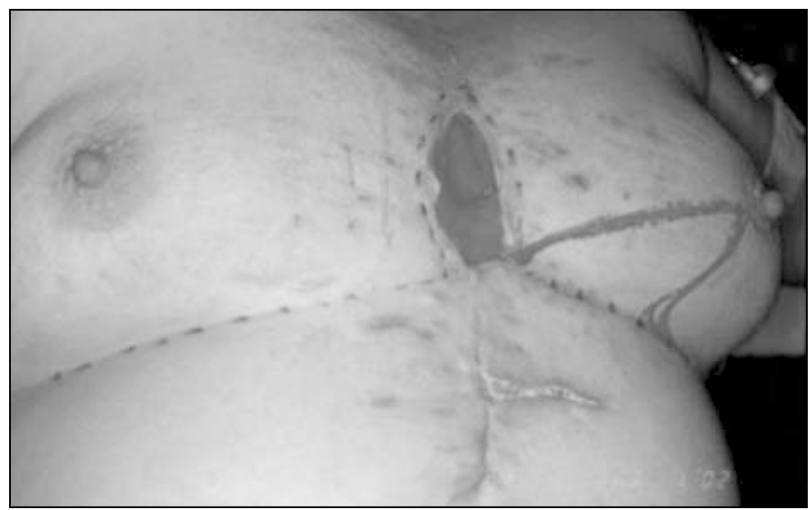

Fig. 4 - Margens de ressecção e Retalho demarcado

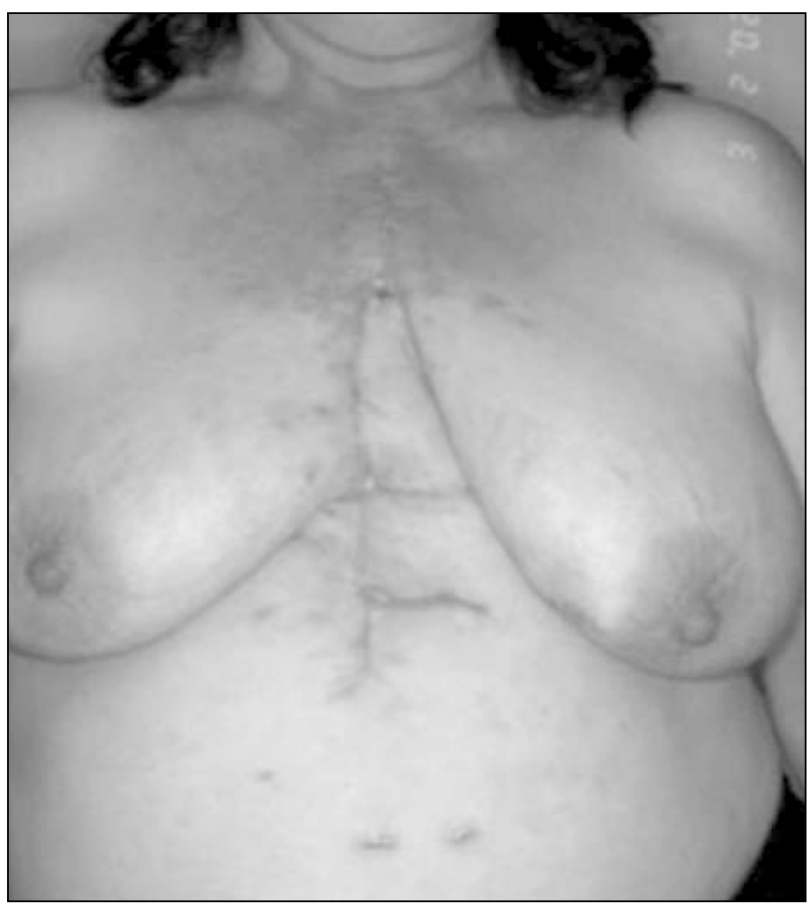

Fig. 5 - Aspecto final com pós-operatório de 30 dias

\section{Discussão}

As complicações da esternotomia dependem da técnica cirúrgica empregada bem como das condições gerais do paciente. Ocorrem com maior freqüência em portadores de hipertensão 
arterial, obesidade, doença pulmonar obstrutiva crônica, diabetes e doenças renais, aumentando a morbi-mortalidade desses pacientes. Algumas situações clínicas são consideradas de maior risco, como o tabagismo, reoperações e um longo período de permanência em terapia intensiva9,10.

Este tipo de paciente freqüentemente apresenta importantes alterações hemodinâmicas e, quando necessária a cobertura da área cruenta esternal, torna-se importante a opção pelos procedimentos de menor risco e que com garantia de maior viabilidade dos tecidos envolvidos.

Após a descrição dos primeiros retalhos músculo-cutâneos e musculares para o tratamento das deiscências de esternotomia ${ }^{2-4,11}$, estes retalhos passaram a ser largamente utilizados e os retalhos cutâneos foram preteridos devido ao conceito da necessidade de um retalho altamente vascularizado. Não há dúvida que o músculo ou o grande omento, quando utilizado como vetores de vascularização, pode fornecer uma segurança maior ${ }^{12,13}$, principalmente nos pacientes de risco elevado. Entretanto, como já foi revisto no tratamento das úlceras de pressão, muitas vezes um retalho cutâneo de dimensões adequadas e com boa vascularização pode ser muito mais efetivo e seguro que um retalho complexo ${ }^{7}$.

Nas ressuturas da esternotomia, as dificuldades de abordagem da parte superior e inferior da incisão envolvem características e condutas distintas. Na porção superior da esternotomia, as bordas são mais facilmente aproximadas e podem ter a vascularização aumentada pela inclusão do músculo peitoral maior no retalho avançado. Este músculo, ao ser liberado, ajuda a preencher a área cruenta central.
Por outro lado, o tratamento da porção inferior da incisão esternal apresenta maiores dificuldades devido a ausência de músculos contíguos disponíveis, que possam ajudar a aumentar a vascularização dos retalhos de pele descolados e avançados. A necrose de bordas com perda de substancia dificulta ainda mais o procedimento. Nos casos mais graves têm sido utilizados os retaIhos músculo-cutâneos do músculo reto abdominal e do músculo grande dorsal ou ainda o omento. Entretanto estas cirurgias são extensas e com uma possibilidade maior de complicações, sobretudo em pacientes com alterações circulatórias ${ }^{14}$. Por sua vez, o retalho de tecido mamário que utilizamos, apresenta um aporte vascular importante e o procedimento cirúrgico para a sua obtenção é pouco agressivo e com menor morbidade. 0 retalho interposto na porção inferior da deiscência favorece a aproximação das bordas sem tensão na sutura final.

A base do retalho descrito está localizada numa região com pedículos arteriais e, se a sua altura for compatível com as dimensões da base, este retalho será bastante seguro. A quantidade de tecido mamário disponível pode preencher a reentrância resultante da necrose dos tecidos na área esternal, propiciando um aporte nutricional para os tecidos em especial ao esterno, às vezes, já expostos há muito tempo.

Embora seja um retalho limitado a quem tem tecido mamário suficiente, deve ser escolhido como primeira opção em pacientes do sexo feminino com deiscência de esternotomia, deixando os retalhos músculo-cutâneos e o retalho de omento para situações clínicas mais complexas. As seqüelas estéticas deste tipo de retaIho são mínimas e bem toleradas pelas pacientes, devido à idade mais avançada e a presença de ptose mamária.

\section{Referências}

1. Lee AB, Schimert G, Shatkin S, et al. Total excision of the sternum and thoracic pedicle transposition of the greater omentum. Surgery. 1976; 80:433.

2. J urkiewicz MJ , Bostwick J, Hester TR, et al. Infected median sternotomy wound: successful treatment by muscle flaps. Ann Surg. 1980; 191:738

3. Jones G, J urkiewicz M J, Bostwick J, et al. Management of the infected median sternotomy wound with muscle flaps. Ann Surg. 1997; 225:766.

4. Nahai F, Rand RP, Hester TR, et al. Primary treatment of the infected sternotomy wound with muscle flaps: a review of 211 consecutive. Plast recons Surg. 1989; 84:434.

5. Pairolero PC, Arnold PG. Management of recalcitrant median sternotomy wounds. J Thorac Cardiovasc Surg. 1884; 88:357.

6. Souza VC, Freire ANM, Tavares-Neto J . Mediastinite pós-esternotomia longitudinal para cirurgia cardíaca: 10 anos de análise. Rev Bras Cir Cardiovasc, 2002; $17(3) 266-270$.

7. Anger J, Militelli N, Monteiro AAJ r, Ferreira MC. Tratamento cirúrgico das úlceras por pressão em pacientes portadores de síndrome de secção medular. Rev Hosp Clin Fac Med São Paulo. 1984: 39:173.
8. Anger J, Militelli N. Tratamento das úlceras trocantéricas por pressão, em pacientes paraplégicos, com retalho músculo-cutâneo do reto femoral. XVIII Congresso Brasileiro de Cirurgia Plástica. 1981.

9. Abboud CS, Wey SB, Baltar VT. Risk factors for mediastinitis after cardiac surgery. Ann Thorac Surg. 2004;77:676-83.

10. The Parisian Mediatinitis Study Group. Risk factors for deep sternal wound infection after sternotomy. J Thorac Cardiovasc Surg. 1996; 111:1200-7.

11. Hallock GG. The breast musculocutaneous flap for complete coverage of the median sternotomy wound. Plast recons Surg. 2003; 112:199-203.

12. J urkiewicz MJ, Arnold PG. The omentum: an account of its use in the reconstruction of the chest wall. Ann Surg. 1977: 185:548.

13. Sampaio DT, Alves J CR, Silva AF, et al. Mediastinite em cirurgia cardíaca: tratamento com epíploon. Rev Bras Cir Cardiovasc. 2000; 15(1),23-31.

14. Domene CE, Volpe P, Onari P, et al. Omental flap obtained by laparoscopic surgery for reconstruction of the chest wall. Surgical laparoscopy \& Endoscopy. 1998; 8 : 215-8. 